\title{
Desempenho do clone AEC144 de Eucalipto inoculado com bactérias diazotróficas no
}

\section{Sudoeste da Bahia}

\author{
Performance of Eucalyptus clone AEC144 inoculated with diazotrophic bacteria in the Southwest \\ of Bahia
}

Comportamiento del clon de Eucalyptus AEC144 inoculado con bacterias diazotróficas en lo suroeste de Bahía

Vitor Alves Monteiro da Silva

ORCID: https://orcid.org/0000-0001-8002-3525 Universidade Estadual do Sudoeste da Bahia, Brasil E-mail: vitor_monteiro96@live.com Joilson Silva Ferreira

ORCID: https://orcid.org/0000-0001-7324-969X Universidade Estadual do Sudoeste da Bahia, Brasil E-mail: joilsonferreira@uesb.edu.br

Rayka Kristian Alves Santos

ORCID: https://orcid.org/0000-0003-2232-8288 Universidade Estadual do Sudoeste da Bahia, Brasil E-mail: raykakristian@yahoo.com.br

Carol Chaves Nascimento

ORCID: https://orcid.org/0000-0002-1873-9757 Universidade Estadual do Sudoeste da Bahia, Brasil

E-mail:carolchavesnascimento4@gmail.com

Vinicius Alves Rodrigues

ORCID: https://orcid.org/0000-0002-5671-7962 Universidade Estadual do Sudoeste da Bahia, Brasil E-mail: vinicius14cnn@gmail.com

Maida Cynthia Duca de Lima

ORCID: https://orcid.org/0000-0002-9946-1258

Universidade Estadual do Sudoeste da Bahia, Brasil E-mail: maidaflorestal@gmail.com

\begin{abstract}
Resumo
A fixação biológica de nitrogênio (FBN) realizada por bactérias diazotróficas é um processo natural e contribui para a viabilidade econômica e sustentabilidade do sistema de produção. Nesse sentido, o presente trabalho objetivou caracterizar bactérias promotoras do crescimento em eucalipto, assim como a interação delas com doses de nitrogênio no desenvolvimento inicial de mudas de eucalipto. As estirpes bacterianas utilizadas no experimento foram JM2R, JN5R, JN6R e LG2F. Realizou-se o experimento em vasos com capacidade de 20L, com delineamento em blocos casualizados (DBC), composto por 3 repetições e fatorial duplo $5 \times 4$, onde o primeiro fator era composto pelos isolados e um controle e, o segundo fator os níveis de nitrogênio $\left(0,25,50\right.$ e $\left.70 \mathrm{~kg} \mathrm{ha}^{-1}\right)$. Os parâmetros avaliados foram altura, número de brotações, massa seca de parte aérea e massa seca de raiz. A interação dos fatores foi significativa, e para altura e massa seca de parte aérea a dose de $70 \mathrm{~kg} \mathrm{ha}^{-1}$ proporcionou as maiores médias.
\end{abstract}

Palavra-chave: Eucalyptus; FBN; Bactéria promotoras de crescimento.

\begin{abstract}
Biological nitrogen fixation (BNF) performed by diazotrophic bacteria is a natural process and contributes to the economic viability and sustainability of the production system. In this sense, the present work aimed to characterize growth-promoting bacteria in eucalyptus, as well as their interaction with nitrogen doses in the initial development of eucalyptus seedlings. The bacterial strains used in the experiment were JM2R, JN5R, JN6R and LG2F. The experiment was carried out in pots with a capacity of 20L, with a randomized block design (DBC), consisting of 3 replications and a 5 44 double factorial, where the first factor was composed of the isolates and a control, and the second factor was nitrogen levels. $\left(0,25,50\right.$ and $\left.70 \mathrm{~kg} \mathrm{ha}^{-1}\right)$. The parameters evaluated were height, number of shoots, shoot dry mass and root dry mass. The interaction of factors was significant, and for height and shoot dry mass, the dose of $70 \mathrm{~kg} \mathrm{ha}^{-1}$ provided the highest means.
\end{abstract}

Keywords: Eucalyptus; FBN; Growth promoting bacteria. 


\section{Resumen}

La fijación biológica de nitrógeno (FBN) realizada por bacterias diazotróficas es un proceso natural y contribuye a la viabilidad económica y sostenibilidad del sistema productivo. En este sentido, el presente trabajo tuvo como objetivo caracterizar las bacterias promotoras del crecimiento en eucalipto, así como su interacción con las dosis de nitrógeno en el desarrollo inicial de las plántulas de eucalipto. Las cepas bacterianas utilizadas en el experimento fueron JM2R, JN5R, JN6R y LG2F. El experimento se realizó en macetas con capacidad de 20L, con un diseño de bloques al azar (DBC), que consta de 3 repeticiones y un factorial doble de $5 \times 4$, donde el primer factor estuvo compuesto por los aislados y un testigo, y el segundo factor fue niveles de nitrógeno $\left(0,25,50\right.$ y $\left.70 \mathrm{~kg} \mathrm{ha}^{-1}\right)$. Los parámetros evaluados fueron altura, número de brotes, masa seca de brotes y masa seca de raíces. La interacción de los factores fue significativa, y para la altura y la masa seca de los brotes, la dosis de $70 \mathrm{~kg} \mathrm{ha}^{-1}$ proporcionó las medias más altas.

Palabras clave: Eucalipto; FBN; Bacterias promotoras del crecimiento.

\section{Introdução}

Atualmente o Brasil possui uma das maiores áreas de florestas plantadas de espécies do gênero Eucalyptus do mundo. Dos 7,83 milhões de hectares de florestas comerciais existentes no território brasileiro, 5,7 ha são correspondentes a plantações de eucalipto (Ibá, 2019). Isso é decorrente da grande quantidade de indústrias de celulose e carvão vegetal, que usam o eucalipto como principal matéria prima, assim, diminuindo o impacto negativo nas florestas nativas.

A resposta do crescimento e produtividade do eucalipto é devido ao equilíbrio de nutrientes, como observado por (Andrade et al., 2006; Faria et al., 2008) as espécies de eucalipto têm um acúmulo nutricional no tronco e na parte aérea que segue a ordem: $\mathrm{N}>\mathrm{Ca}>\mathrm{K}>\mathrm{Mg}>\mathrm{P}$.

Devido à grande demanda de $\mathrm{N}$ pela cultura e os preços elevados do adubo busca-se alternativas para suprir a falta desse elemento, neste contexto a fixação biológica de nitrogênio é essencial, o qual visa obter máximos de produtividade com a melhor relação custo/benefício e impacto ambiental mínimo (Hungria et al., 2007).

A utilização de bactérias que promovem o crescimento das plantas é muito importante, vai além do suprimento inicial de nitrogênio, desempenham funções como produção de fitohormônios, controle de patógenos, solubilização de nutrientes e disponibilização para as plantas (Melo et al., 2012; Matoso et al, 2016; Viana et al., 2015; Weirich et al., 2018; Alves et al., 2020; Martins et al., 2020).

Atualmente, processos que visem a redução de produtos sintéticos e auxiliem na sustentabilidade do ecossistema, é cada vez mais necessário, desta forma a associação de bactérias diazotróficas é essencial para esse crescimento inicial sustentável e econômico na cultura do eucalipto.

Nesse sentido, objetivou avaliar a ação destas bactérias com a interação de doses de nitrogênio no crescimento inicial de mudas de eucalipto.

\section{Metodologia}

O trabalho é uma análise experimental em campo para avaliação da inoculação de bactérias e adubação nitrogenada em eucalipto, foi realizado no período de março de 2019 à agosto de 2019, no Laboratório de Microbiologia do Solo e em área experimental da Universidade Estadual do Sudoeste da Bahia - UESB, campus de Vitória da Conquista, cujas coordenadas geográficas são $14^{\circ} 51^{\prime}$ latitude sul e 40 $50^{\circ}$ ' longitude oeste, a 928m de altitude. O clima na região é tropical de altitude (Cbw), segundo a classificação de Köeppen, as médias de temperatura máxima e mínima são, respectivamente, 25,3 e $16,1^{\circ} \mathrm{C}$.

A reativação das bactérias foi realizada com meio de cultura DYGS líquido (Döbereiner et al., 1999) incubada em estufa BOD para crescimento das mesmas, posteriormente, houve a transferência de $1 \mathrm{~mL}$ da suspensão bacteriana crescida para frascos de vidros de penicilina dos meios semissólidos. Os frascos foram incubados na BOD a $30^{\circ} \mathrm{C}$ até o crescimento e purificação das mesmas, para que houvesse a repicagem para os meios sólidos que gerariam os isolados para a produção do inoculante líquido em meio DYGS líquido para aplicação nos vasos após o plantio. 
O experimento foi realizado em vasos com capacidade de 20L nos quais realizou o plantio das mudas padronizadas do clone AEC144 (Eucalyptus urophylla), foi utilizado substrato proveniente da área experimental do campus, onde a análise química apresentou os seguintes parâmetros $\mathrm{pH}=4,5 ; \mathrm{P}=1 \mathrm{mg} \mathrm{dm} 3 ; \mathrm{K}+=0,8 \mathrm{cmolc} / \mathrm{dm}^{3}$ de solo e $\mathrm{Ca}^{2+}=0,8 \mathrm{cmolc} / \mathrm{dm}^{3} \mathrm{de}$ solo, que foi corrigido de acordo com as recomendações da cultura pela $5^{a}$ aproximação de Ribeiro et al., (1999). O delineamento experimental usado foi em blocos casualizados (DBC) com três repetições, totalizando 60 vasos, em fatorial duplo $5 \times 4$, o primeiro fator sendo isolados bacterianos e o segundo fator doses de $\mathrm{N}$ aplicadas ao substrato.

A inoculação foi realizada com os isolados (JM2R, JN5R, JN6R e LG2F) seguidas de um controle sem inoculação, assim como as doses de Ureia $\left(0,25,50\right.$ e $\left.70 \mathrm{~kg} \mathrm{ha}^{-1}\right)$. Após o período de 80 dias, avaliou-se o crescimento inicial das plantas em altura com régua graduada, número de brotações, massa seca de parte aérea e raiz em estufa com $60^{\circ}$ por 72 horas.

Os dados obtidos foram submetidos à análise de variância e a comparação das médias pelo Teste de Scott-knott a 5\% de probabilidade, e avaliação dos parâmetros quantitativos por regressão linear e quadrática. Para aplicação dos testes foi utilizado o programa SISVAR (Ferreira, 2011).

As variáveis obtidas com isolados bacterianas foram correlacionadas com todas as variáveis fitotécnicas utilizando-se a análise de correlação de Pearson. Adotou-se $\alpha=0,05$.

\section{Resultados e Discussão}

Observa-se a ação do fator isolado bactéria (Tabela 1), a diferença significativa entre as bactérias só ocorreu no número de brotações, onde o isolado JM2R apresentou uma resposta de 37,86\% superior a testemunha sem inoculação. Em relação à altura o isolado JN6R apresentou um incremento de 3,36\% e em massa seca de raiz esse incremento foi de 1,60\% em relação a testemunha, em massa seca de parte aérea o isolado JM2R incrementou 13,79\%.

Nascimento et al., (2021) estudando inoculação em eucalipto não encontraram diferença entre os isolados bacterianos utilizados mas observou que altura e o diâmetro apresentaram incrementos de $2,92 \%$ e 6,38\%, respectivamente em relação ao controle.

Tabela 1. Média geral de altura (ALT), massa seca de parte aérea (MPA), massa seca de raiz (MRA) e número de brotação (BROT), de mudas de eucalipto inoculadas com isolados bacterianos.

\begin{tabular}{lllll}
\hline Bactérias & ALT & MPA & MRA & BROT \\
\hline JM2R & $43,10 \mathrm{~A}$ & $20,05 \mathrm{~A}$ & $38,14 \mathrm{~A}$ & $30,33 \mathrm{~A}$ \\
JN5R & $43,62 \mathrm{~A}$ & $17,89 \mathrm{~A}$ & $31,52 \mathrm{~A}$ & $24,16 \mathrm{~B}$ \\
LG2F & $43,99 \mathrm{~A}$ & $17,79 \mathrm{~A}$ & $29,43 \mathrm{~A}$ & $20,91 \mathrm{~B}$ \\
JN6R & $44,80 \mathrm{~A}$ & $18,97 \mathrm{~A}$ & $32,95 \mathrm{~A}$ & $24,50 \mathrm{~B}$ \\
Controle & $43,34 \mathrm{~A}$ & $17,62 \mathrm{~A}$ & $39,32 \mathrm{~A}$ & $22,00 \mathrm{~B}$
\end{tabular}

Médias seguida de mesma letra na coluna não diferem entre si pelo teste de Scott-Knott a 5\% de significância. Fonte: Autores.

A biofertilização com bactérias promotoras do crescimento é responsiva em diversas culturas com resultados em desenvolvimento inicial de plântulas, maior área foliar, diâmetro de colmo, crescimento e volume radicular e teor relativo de clorofila (Sousa et al. 2012; Dartora et al.,2013; Sivasakthivelan \& Saranraj 2013; Inagaki et al.,2014; Inagaki et al.,2015; Rampim et al., 2020).

Quando avaliado o fator isolado observamos a importância da interação com a adubação, sabe-se que essas bactérias necessitam de um estímulo que é gerado a partir dos exsudatos liberados pelas raízes, para isso antes mesmo que o processo comece a própria planta deve está apta a emitir sinais e esses fatores são dependentes de diversas questões como, a interação 
entre a comunidade microbiana do solo, as condições do solo e ambiente.

Diferentemente do atual trabalho, Santos et al., (2021) observou que a inoculação de isolados nativos em eucalipto diferenciou significativamente da testemunha e apresentou um incremento de 15,20\% em altura e 39,52\% em massa seca de raiz.

É importante salientar que mesmo que não seja significativo estatisticamente o incremento obtido após a inoculação é muito importante, a ação é benéfica no crescimento e isso auxilia a planta posteriormente em sua rusticidade no campo e futuramente reflete em produtividade.

Levando em consideração que o eucalipto é uma espécie florestal com crescimento mais lento onde dura cerca de 7 anos para atingir seu início de corte e consequente maturação, o tempo em que é avaliado a ação destas bactérias é curto, mas mesmo que não seja significativo estatisticamente é importante salientar o incremento em relação a testemunha, que se dá em resposta das funções de promoção de crescimento, seja elas pela produção de hormônios por essas bactérias ou pela maior disponibilização de nitrogênio para as plantas.

Seguiu-se a análise da interação dos fatores e seu desdobramento, sendo apresentado os resultados gráficos somente das bactérias que apresentaram a significância do R acima de $50 \%$.

Para massa seca de raiz não houve significância da interação levando em consideração o coeficiente de determinação da equação e a significância dos parâmetros estudados.

Todas as características apresentaram comportamento linear para a interação dos fatores, sendo assim os valores médios de altura 46,23 cm com o isolado JM2R (Figura 1). Para massa seca de parte área os valores médios foram de 25,20 g; 31,19 g, 20,04 g e 22,67 g e 21,45 g para controle, JM2R, JN5R, JN6R e LG2F, respectivamente (Figura 2).

Figura 1. Médias de altura em função da adubação nitrogenada com ureia e inoculação bacteriana.

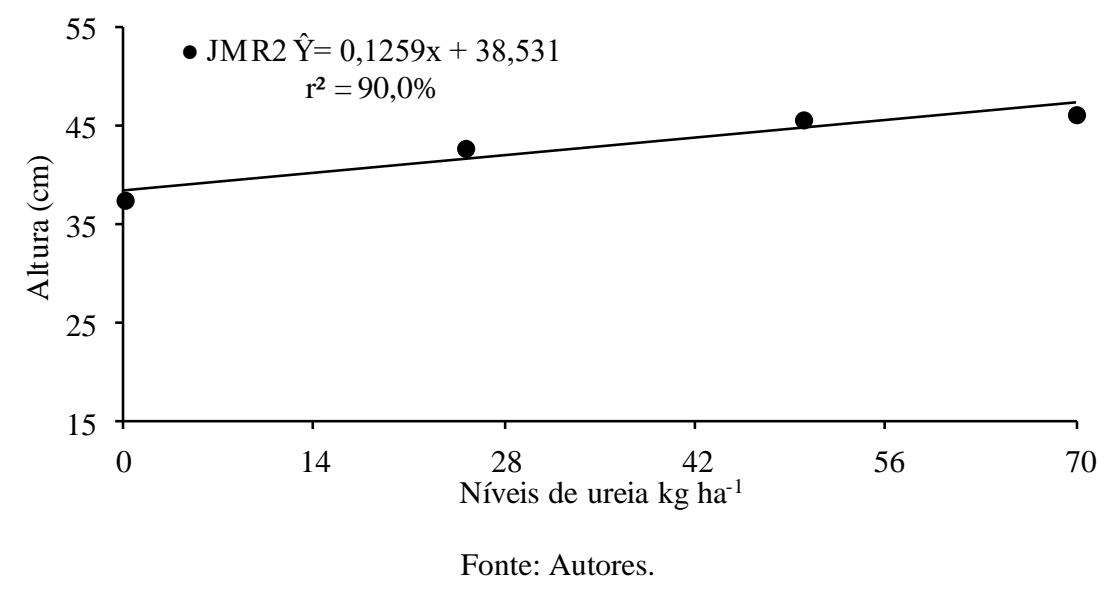


Figura 2. Médias de massa seca de parte aérea em função da adubação nitrogenada e inoculação bacteriana.

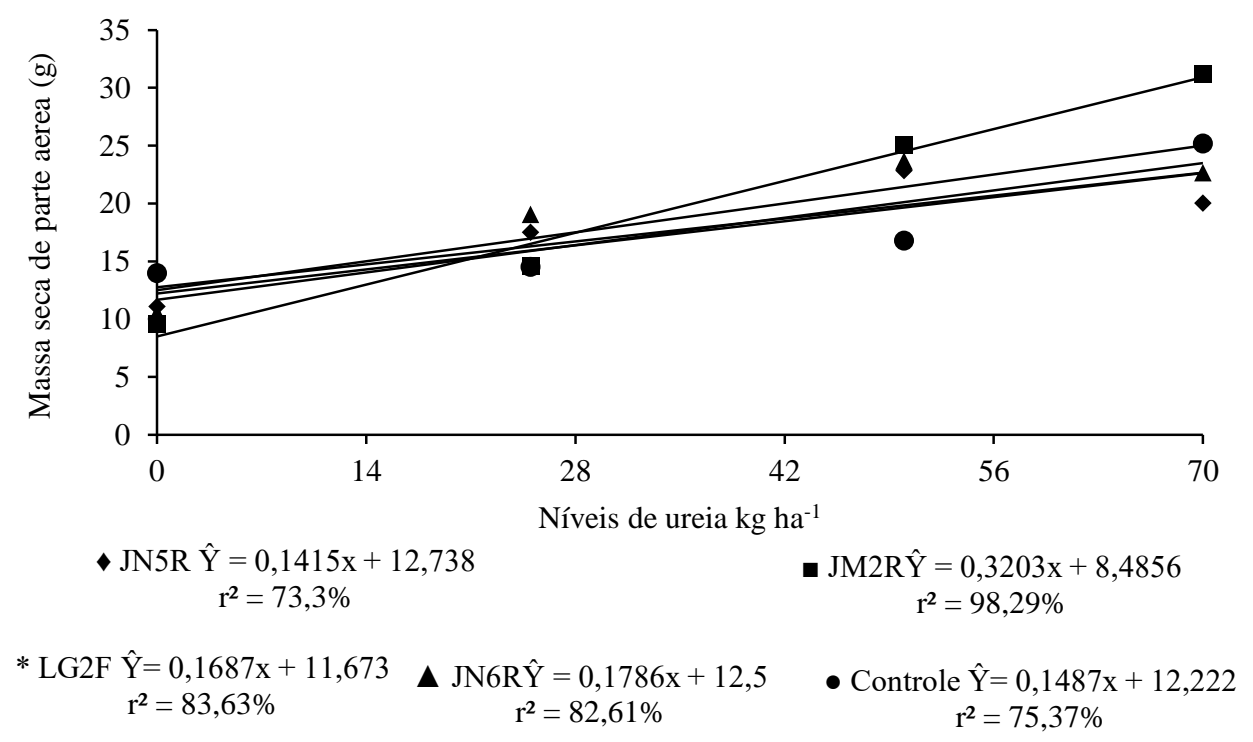

Fonte: Autores.

Em relação ao número de brotações laterais nas plantas, elas também seguiram uma tendência linear dos dados sendo que os valores foram de 29,66; 39,33 e 39,00 para o Controle, JM2R e JNFB6R respectivamente, no nível de 70 kg ha ${ }^{-1}$ de $\mathrm{N}$ (Figura 3).

Figura 3. Médias de massa seca de número de brotações em função da adubação nitrogenada e inoculação bacteriana.

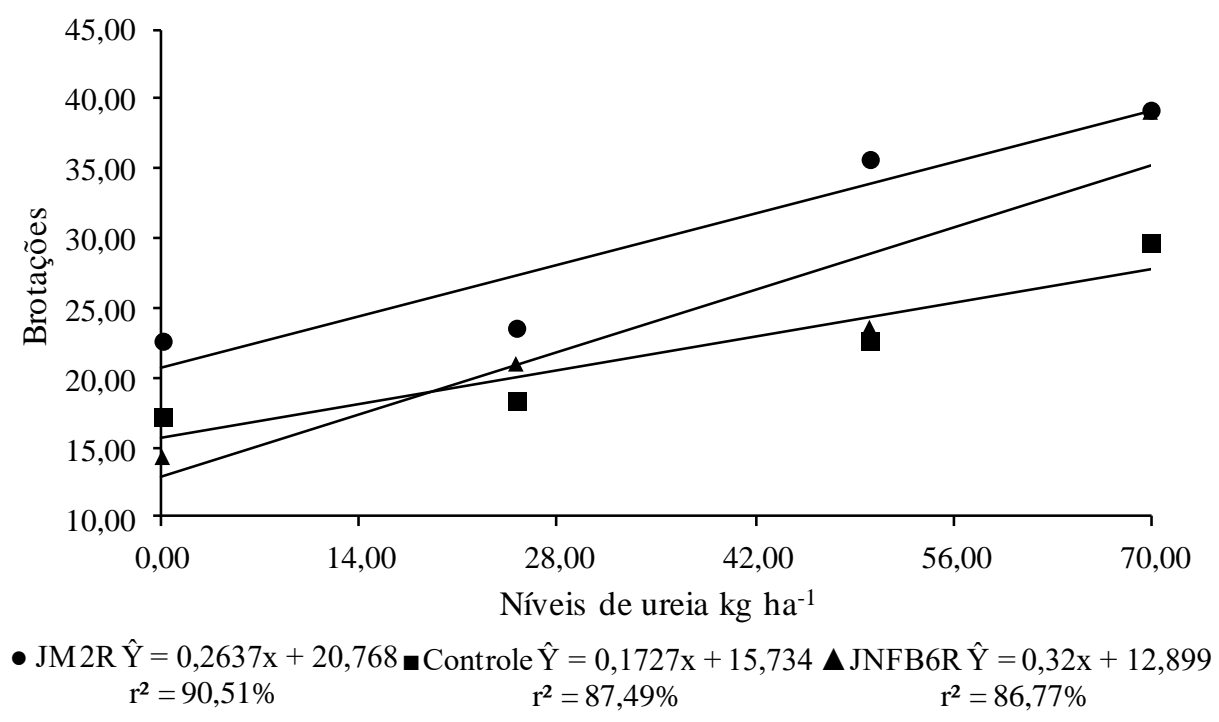

Fonte: Autores.

Observa-se que a bactéria JM2R foi responsiva em todas as características e apresentou as maiores médias quando comparada com as outras bactérias, quando associada a dose de $70 \mathrm{~kg}$ de $\mathrm{N}$ ela conseguiu resposta de 19,98\%, 197,16\% e 95\% superior quando estava sozinha, sem associação com o N.

A análise multivariada dos dados apresentou uma correlação positiva entre as características, assim observa-se (Tabela 2) que o Número de Brotações e Massa seca de parte aérea se correlacionam fortemente e positivamente, da mesma 
forma que Altura e Massa seca de parte aérea tem a mesma correlação. É importante salientar com esses resultados que a associação com a inoculação interferiu no crescimento das plantas principalmente no acúmulo de massa seca, característica muito importante que isso reflete posteriormente em produtividade da cultura.

Tabela 2. Correlação de Pearson em dados de eucalipto submetido a inoculação bacteriana e adubação nitrogenada.

\begin{tabular}{lrrrr}
\hline \multicolumn{1}{c}{ Variáveis } & Brotação & Altura & $\begin{array}{c}\text { Massa seca de } \\
\text { parte aérea }\end{array}$ & $\begin{array}{c}\text { Massa seca de } \\
\text { raiz }\end{array}$ \\
\hline Brot & 1 & $0,360^{*}$ & $0,639^{*}$ & $0,229^{\text {ns }}$ \\
Alt & & 1 & $0,625^{*}$ & $0,139^{\text {ns }}$ \\
MPA & & & 1 & $0,309^{*}$ \\
MRA & & & & 1 \\
\hline
\end{tabular}

Significativo $*(\mathrm{P} \leq 0,05)$. Fonte: Autores.

Nascimento et al., (2021) avaliando correlação em eucalipto inoculado e adubado com sulfato de amônio, também observou correlação positiva forte entre brotação, altura e massa seca de parte aérea. Farias et al. (2017) correlacionam o desenvolvimento futuro do povoamento florestal, com o arranque inicial das plantas em altura e em diâmetro devido à adubação nitrogenada.

Diante dos resultados concretiza a importância do estudo desses biofertilizantes que maximizem o uso do nitrogênio acarretando em menos custos ao produtor e maior sustentabilidade agrícola, o uso de bactérias diazotróficas na cultura do eucalipto promove o crescimento em massa seca e altura das plantas que pode favorecer posteriormente a manutenção da planta no campo e maior resposta posteriormente em produtividade.

\section{Conclusão}

A interação das bactérias com a adubação nitrogenada na dose de $70 \mathrm{~kg} \mathrm{ha}^{-1}$ promovem respostas em altura, número de brotações e massa seca de parte aérea.

A bactéria JM2R promoveu maior resposta em crescimento das plantas quando associada a dose de $70 \mathrm{~kg} \mathrm{ha}^{-1}$.

Trabalhos futuros pode ser estudado a interação com diferentes fontes de nitrogênio e doses superiores para que elucide a ação das bactérias tanto no crescimento inicial das plantas quanto nas fases após plantio em campo.

\section{Referências}

Alves, M. V., Nesi, C. N., Naibo, G., Barreta, M. H., Lazzari, M., Júnio R, A. F., \& Skoronski, E. (2020) Corn seed inoculation with Azospirillum brasilense in different nitrogen fertilization management. Revista Brasileira de Ciências Agrárias (Agrária), 15(3).

Andrade, G. C., Bellote, A. F. J., Silva, H. D., Rizzi, N. E., \& Gava, J. L. (2006) Acúmulo de nutrientes na biomassa e na serapilheira de Eucalyptus grandis em função da aplicação de lixo urbano e de nutrientes minerais. Boletim de Pesquisa Florestal, Colombo, (53), $109-136$.

Dartora, J., Guimarães, V.F., Marini, D., \& Sander, G. Adubação nitrogenada associada à inoculação com Azospirillum brasilense e Herbaspirillum seropedicae na cultura do milho (2013). Revista Brasileira de Engenharia Agrícola e Ambiental,17(10),1023-1029.

Döbereiner, J., Andrade, V. de O., \& Baldani, V. L. D (1999). Protocolos para Preparo de Meios de Cultura da Embrapa Agrobiologia. Seropédica: Embrapa Agrobiologia, 38p.

Faria, G. E., Barros, N. F., Cunha, V. L. P., Martins, I. S., \& Martins, R. C. C. (2008) Avaliação da produtividade, conteúdo e eficiência de utilização de nutrientes em genótipos de Eucalyptus spp. no Vale do Jequitinhonha, MG. Ciência Florestal, 18(3), $363-373$.

Ferreira D. F. (2011). Sisvar: A computer statistical analysis system. Ciência e Agrotecnologia, 35(6), 1039-1042.

Hungria, M., Campo, R. J., \& Mendes, I. C. (2007) A importância do processo de fixação biológica do nitrogênio para a cultura da soja: componente essencial para a competitividade do produto brasileiro. Londrina: Embrapa Soja, 80p. (Embrapa Soja. Documentos, 283)

Indústria Brasileira de Árvores - IBÁ. Relatório Anual IBÁ - 2019. Indicadores de desempenho do setor nacional de árvores plantadas referentes ao ano de 2018. https://www.iba.org/datafiles/publicacoes/relatorios/ibarelatorioanual2019.pdf. 
Research, Society and Development, v. 11, n. 2, e29211225589, 2022

(CC BY 4.0) | ISSN 2525-3409 | DOI: http://dx.doi.org/10.33448/rsd-v11i2.25589

Inagaki, A. M., Guimaraes, V. F., Lana, M. C., Klein, J., Costa, A. C. P. R., Rodrigues, L. F. O. S., \& Rampim, L. (2015). Maize initial growth with the inoculation of plant growth-promoting bacteria (PGPB) under different soil acidity levels. Australian Journal of Crop Science, 9(4), 271-280.

Inagaki, A. M., Guimarães, V. F., Rodrigues, L. F. O. S., Silva, M. B., Diamante, M. S., Rampim, L., Mioranza, T. M., \& Duarte Júnior, J. B. (2014) Phosphorus fertilization associated to inoculation of maize with diazotrophic bactéria. African Journal of Agricultural Research, 9(48), 3480-3487.

Martins, M. B. F., Santos, A. H. S., Carvalho, C. T., Azeredo, G. A., \& Oliveira, F. L. N. (2020) Biofertilizante de torta de filtro e bactéria promotora do crescimento em plantas na produção de mudas de alface. Brazilian Journal of Development, 6 (9): 67758 - 67768

Matoso, E. S., Marco, E., Bellé, C., Rodrigues, T. A., \& Anjos e Silva, S. D. (2016) Desenvolvimento inicial de mudas pré-brotadas de cana-de-açúcar inoculadas com bactérias diazotróficas. Revista Jornal Pós-Graduação e Pesquisa, 13: 412-434.

Melo, L. C., Oliveira, C. V. de Manfredi, C., Baldani, V. L. D., \& Ferreira, J. S. (2012) Efeito de bactérias na promoção do enraizamento em clone de eucalipto. Enciclopédia Biosfera, 8 (15): 736-747.

Nascimento, C. C. et al., 2021. Desenvolvimento de Eucalyptus urophylla submetido à inoculação de bactérias diazotróficas nativas. (2021) Brazilian Journal of Development, 7(5), 47287-4730.

Rampim, L., Guimarães, V. F., Salla, F. H., Costa, A. C. P. R. da, Inagaki, A. M., Bulegon, L. G., \& França, R. de. (2020) Initial development of reinoculated maize seedlings with diazotrophic bacteria. Research, Society and Development, 9(5), e24953109.

Ribeiro, A. C., Guimarães, P. T. G., \& Alvarez, V. V. H. (Ed.). (1999) Recomendações para o uso de corretivos e fertilizantes em Minas Gerais: $5^{a}$ aproximação. Viçosa, MG: Comissão de Fertilidade do Solo do Estado de Minas Gerais, p. 179.

Santos, R. K. A., Ferreira, J. S., Paula, R. C. de. Rodrigues, V. A., Silva, V. A. M. da. \& Santos, J da S. (2021) Plant growth-promoting bacteria associated with nitrogen fertilization in Eucalyptus urophylla Increase Growth. Holos. 37(2), 1-14.

Sivasakthivelan, P., \& Saranraj, P. (2013) Azospirillum and its Formulations: A Review. International Journal Microbiological Research 4(3),275-287.

Sousa, R. F. B., Guimaraes, V. F., Pinto Junior, A. S., \& Oro, T. H. (2012) Avaliação da qualidade sanitária de sementes de milho provenientes do cultivo associado com Azospirillum brasilense e Herbaspirillum seropedicae. Revista Cultivando o Saber,5(4),213-218.

Viana, T. O., Santos, J. S., Manfredi, C., Moreira, R. V. S., Baldani, V. L. D., \& Ferreira, J. S. (2015) Isolation and inoculation of diazotrophic bacteria in rice (Oryza sativa L.) grown in Vitoria da Conquista-BA. African Journal of Agricultural Research, v. 10, n. 29, p. 2847-2854.

Weirich, S. W., Silva, R. F., Perrando, E. R., Ros, C. O., Dellai, A., Scheid, D. L., \& Trombeta, H. W. (2018) Influência de ectomicorrizas no crescimento de mudas de Eucalyptus grandis, Corymbia citriodora, Eucalyptus saligna e Eucalyptus dunnii. Ciência Florestal, 28 (2): 765-777. 